\title{
From Shadow: uma pesquisa em design conduzida pela prática sobre ansiedade acadêmica
}

Kiarna Michie é estudante de Mestrado em Design com bacharelado tendo por foco Design de Comunicação, ambas na Universidade de Tecnologia de Auckland, Nova Zelandia. Ao longo de sua graduação, ela desenvolveu habilidades em imagem em movimento e tem experiência de trabalho em projetos de pesquisa que envolvem narrativa criativa, ilustração, colagem e vivência.

<kiarna.michie@aut.ac.nz>

ORCID: 0000-0002-1299-9574
Resumo Esta pesquisa utiliza métodos de pesquisa autoetnográfica e fenomenológica para investigar, projetar e ilustrar as formas como a ansiedade acadêmica se manifesta na experiência humana. $O$ diário é usado para destilar um relato subjetivo em temas lúcidos que dão forma e caráter a algo tão complexo e multifacetado como a ansiedade causada pelo estresse acadêmico em um ano de COVID-19. Uma questão central desta pesquisa é descobrir como as técnicas de colagem, na forma de cartas temáticas, podem ser capazes de comunicar, refletir e provocar uma ressonância emocional e uma autoconsciência em relação à natureza multifacetada da ansiedade. From Shadows é o artefato resultante produzido a partir dessa pesquisa.

Palavras chave Design, Practice-led, Pesquisa conduzida pela prática, From Shadows. 


\section{From Shadow: a practice-led design research on academic anxiety'}

Marcos Mortensen Steagall é professor e coordenador do Curso de Design da Auckland University of Technology (AUT) - South Campus. Possui ampla experiência no conhecimento, desenvolvimento e implementação de currículos educacionais, liderando os esforços de equipes acadêmicas. Mestre e Doutor em Comunicação e Semiótica. Em 2015, mudou-se para Aotearoa, Nova Zelândia, para realizar pesquisa conduzidas por prática artística, que resultou em novo doutorado defendido em 2018 na própria AUT. <marcos.steagall@aut.ac.nz> ORCID: 0000-0003-2108-4445
Abstract This research utilises auto ethnographic and phenomenological research methods to investigate, design and illustrate the ways that academic anxiety manifests in the human experience. Where the journal is used to distil a subjective account into lucid themes that provides form and character to something as complex and multifaceted as Anxiety caused by academic stress in a year of COVID-19. A question posited at the centre of this research is to discover, how might collage illustration techniques in the form of thematic cards, might be able to communicate, reflect and provoke an emotional resonance and self-awareness regarding the protean nature of anxiety. From Shadows is the resultant design artifact produced from this research.

Keywords Design, Practice-led, Practice-led research, From Shadows.

From Shadow: una investigación de diseño dirigida por la práctica sobre la ansiedad académica

Resumen Esta investigación utiliza métodos autoetnográficos y fenomenológicos para investigar, diseñar e ilustrar las formas en que la ansiedad académica se manifiesta en la experiencia humana. Donde la revista se utiliza para destilar un relato subjetivo en temas lúcidos que le dan forma y carácter a algo tan complejo y multifacético como la ansiedad provocada por el estrés académico en un año de COVID-19. Una pregunta planteada en el centro de esta investigación es descubrir cómo las técnicas de ilustración de collage en forma de tarjetas temáticas podrían comunicar, reflexionar y provocar una resonancia emocional y autoconciencia sobre la naturaleza proteica de la ansiedad. From Shadows es el artefacto de diseño resultante producido a partir de esta investigación.

Palabras clave Diseño, Practice-led, Investigación dirigida por la práctica, From Shadows. 


\title{
Contextualização teórica
}

\author{
Ansiedade
}

A ansiedade é conhecida por ser um tema complexo, que pode ser examinada por vários ângulos, sejam eles psicológicos, fisiológicos, filosóficos, sociais e culturais. (SWIFT et al., 2014). Apesar de normalmente se pesquisar este tema a partir de uma vivência qualitativa fenomenológica, é imprescindível compreender o fenômeno a partir de uma perspectiva acadêmica. De acordo com Korstjens \& Moser (2017, p.274): “A pesquisa qualitativa leva em consideração os contextos naturais nos quais os indivíduos ou grupos funcionam para fornecer uma compreensão aprofundada dos problemas do mundo real".

A ansiedade pode ser entendida como uma emoção humana evolutivamente adaptativa e que funciona biologicamente como um sistema de alerta ao perigo e às ameaças, possibilitando uma maior chance de sobrevivência. Assim, quando ocorrem sentimentos de ansiedade, é porque o indivíduo percebe o perigo iminente em seu ambiente (MOSS, 2003).

$\mathrm{O}$ que distingue a ansiedade do medo é que, com a ansiedade, o indivíduo não consegue identificar qual é a ameaça. A ansiedade é caracterizada pela incerteza quanto à possibilidade futura de uma experiência negativa imperceptível que se possa sentir (STEIMER, 2002). A filosofia sustenta a ideia de que a ansiedade se origina de nossa consciência e o medo de nossa morte eventual. o filósofo grego estóico Sêneca argumentou que: "o homem que teme a morte nunca fará nada digno de um homem que está vivo" (WILSON, 2014, p.72). Kierkegaard (2000), Heidegger (1977) e filósofos existencialistas ampliaram os pensamentos de Sêneca, considerando que a raiz da ansiedade é a compreensão do homem de que sua existência é finita. Uma maneira de escapar das garras da ansiedade é devotar a atenção ao presente em vez de se preocupar com o futuro (CROCQ, 2015).

Embora existam alunos que obtêm sucesso em um ambiente acadêmico estressante, muitos outros lutam diante dos desafios apresentados ao longo do caminho para a obtenção de um diploma - e isso pode se tornar mais prejudicial com o tempo (HOODA \& SAINI, 2017). A ansiedade acadêmica é associada a quatro componentes principais: preocupação, emotividade, interferência gerada por tarefa e déficits de habilidades de estudo. Este tipo específico de ansiedade, resultante das pressões do ambiente de aprendizagem, pode causar um forte impacto no desempenho do aluno e levar a formas associadas a tendências específicas de expectativas acadêmicas (ALPERT \& HABER, 1960; HEMBREE, 1990). 


\section{Fenomenologia}

No contexto desta pesquisa, a fenomenologia é entendida como uma abordagem de pesquisa que visa encontrar uma compreensão mais profunda da experiência individual e subjetiva do mundo, especificamente por meio de padrões de consciência e das formas como atribuímos significado à nossa realidade. É um campo de pesquisa com uma sólida formação teórica, contando com fenomenólogos importantes como Edmund Husserl e Martin Heidegger. Segundo Husserl (1913), realizar um estudo fenomenológico é refletir e descrever ativamente um fenômeno ou uma experiência individual usando os sentidos.

Esta pesquisa é considerada fenomenológica por ter investigado criticamente uma experiência pessoal com a ansiedade, por meio de um diário retrospectivo sobre os aspectos emocionais e sensoriais ocorridos em relação ao fenômeno (PATTON, 1980).

\section{Collage cards}

Em termos de formato da colagem, a decisão foi criar cartões temáticos. Inspirado no baralho do tarô, From Shadows é um projeto carregado de simbolismo e metáforas. As cartas de tarô são conhecidas na cultura pop como uma forma de baralho usada para adivinhação e previsão do futuro. A pesquisa explorou o tarô como um suporte significativo dentro de um contexto terapêutico que permite aos participantes identificar novas perspectivas, aspirações e desejos (HOFER, 2009).

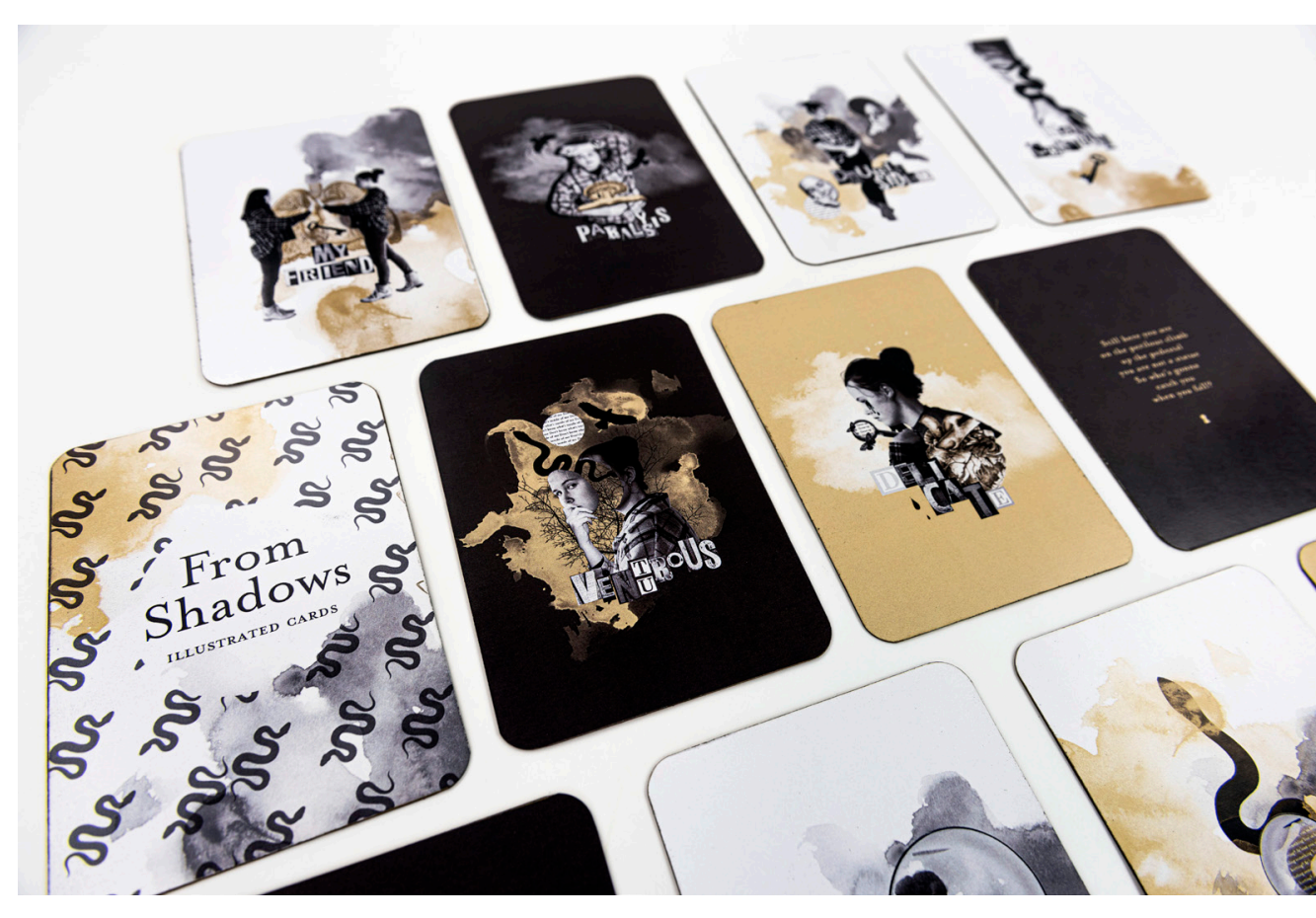


Dentro deste estudo, foram feitas perguntas específicas aos participantes para inspirar a reflexão sobre os significados das cartas. Ao formatar as ilustrações temáticas em cartões frente e verso, o trabalho pôde provocar uma conexão emocional com o conteúdo ilustrativo da parte frontal da carta por meio da poesia. Nesse sentido, as cartas tornam-se uma ferramenta para inspirar o pensamento pessoal sobre a ansiedade. Ter elementos escritos em conjunto com o design visual fortalece o tema da colagem e favorece uma transmissão multifacetada da ansiedade por meio da comunicação visual.

\section{Poesia Lírica}

O estudo inclui versos poéticos que acompanham as ilustrações das colagens com o objetivo de evocar uma ressonância emocional sobre a experiência da ansiedade. A força da poesia está em sua habilidade de trazer nossas emoções à existência não apenas para nossa autocompreensão, mas também ressoar em outras pessoas. $O$ ato de usar a palavra 'eu' na narrativa pessoal permite que a pesquisadora alcance uma vulnerabilidade e profundidade na qual o trauma e o self podem ser despertados e confrontados - permitindo um senso de coerência e consciência através das ideias que escolhemos focar ao escrever poesia. $O$ poeta americano Gregory Orr defende o gênero da poesia lírica:

$\mathrm{Na}$ lírica, o self encontra uma crise existencial em forma simbólica (...). O self pode reconhecer a existência do que o está desestabilizando (...) Quando alguém em meio a uma experiência poderosa e perturbadora se volta para a escrita e leitura de um poema, é porque sente que a lírica pode ser uma ajuda poderosa para ajudar a sobreviver e dar sentido a sua experiência. (ORR, 2002)

\section{Metodologia}

\section{Autoetnografia}

A metodologia de pesquisa pode ser entendida como o sistema ou plano de ação para estruturar ou conduzir um projeto de pesquisa. Esse processo inclui a maneira como coletamos, interpretamos e analisamos os dados e as técnicas de coleta desses dados que informam os resultados da pesquisa (IGWENAGU, 2016). A metodologia permite que o pesquisador esclareça os métodos de pesquisa e avalie construtivamente o processo, ao mesmo tempo em que confronta quaisquer suposições anteriormente assumidas em relação à pesquisa. 
Esta pesquisa situa-se como uma forma de autoinvestigação em que os métodos são predominantemente qualitativos. Cada vez mais, pesquisadores nas áreas das artes e do design reconhecem o valor dos modos não tradicionais de conhecimento e representação. Essa pesquisa se estrutura na premissa de de que nenhuma verdade ou interpretação da realidade deve ser privilegiada, mas que é moldada pelas nuances da experiência individual. (BUTLER-KISBER, 2008). Este tipo de pesquisa é uma investigação crítica de contextos sociais, culturais e políticos usando uma abordagem qualitativa, em oposição ao paradigma positivista tradicional. (TROCHIM \& DONNELLY, 2016)

Tomamos emprestados os métodos usados nas metodologias de pesquisa fenomenológica e autoetnográfica para situar uma autoinvestigação sobre uma experiência pessoal de ansiedade. Como tal, a pesquisa gravita em direção a um paradigma pós-positivista (DENZIN \& LINCOLN, 2008). Como parte da metodologia, foram utilizados elementos da autoetnografia para analisar a experiência pessoal. Para ser mais específico, o estudo não foi escrito em um estilo autobiográfico completo, mas sim, usando elementos do relato da pesquisadora por meio de registros em diário para inspirar a prática de design e da poesia sobre a ansiedade experimentada - já que a questão de pesquisa se concentra em evocar uma ressonância emocional através da dissecção e comunicação de uma experiência pessoal em um resultado de design visual.

A autoetnografia é uma estrutura para pesquisa e escrita que considera a experiência do pesquisador para descobrir o conhecimento sobre um fenômeno cultural ou social. Conforme observado por Ellis et al. (2011), a autoetnografia mescla métodos de pesquisa de autobiografia e etnografia. Para muitas formas de autoinvestigação artística, a análise crítica da criação ocorre retrospectivamente, o que significa que é dependente da memória do pesquisador sobre o que ocorreu na prática. É por isso que alguns autores consideram a autoetnografia um método duvidoso ou errôneo (SKAINS, 2016).

No entanto, isso pode ser contrabalançado por meio de uma análise rigorosa e do emprego da reflexão autodirigida no início da criação e durante todo o processo. Para tanto, a pesquisadora mantém ativamente um diário, registrando percepções sobre o processo e que podem ser revisadas posteriormente. L. Richardson \& St. Pierre (2008) utilizam o termo "processo analítico criativo" para descrever esse registro subjetivo necessário dentro da pesquisa etnográfica. A forma que a pesquisa garantiu a reflexão ativa do processo criativo se deu por meio do registro dos pensamentos e ideias da pesquisadora que surgiram ao criar as colagens, questionando as formas como a prática se relaciona com a experiência da ansiedade, e delineando as ações que funcionaram e as que desviaram da área inicial de investigação ou questão de pesquisa. Essa ideia pode ser vista na entrada de diário correspondente. 
As expectativas acadêmicas dentro do ensino médio geram um senso doentio de competitividade entre os alunos. Somos segregados em turmas rotuladas de classes avançadas, convencionais e de desenvolvimento, também conhecidas como 'repolho'. Os alunos seriam transferidos entre essas classes de acordo com as notas. Observei e senti momentos em que as notas determinaram meu senso de autoestima e, na pior das hipóteses, testemunhei o rompimento de amizades . (MICHIE, 2020, p.21).

Foi a partir desse trecho que a pesquisadora pôde olhar o conteúdo da escrita de forma mais ampla. Foi descoberto o tema da ansiedade que se manifesta devido à pressão na educação para atingir padrões elevados de rendimento.
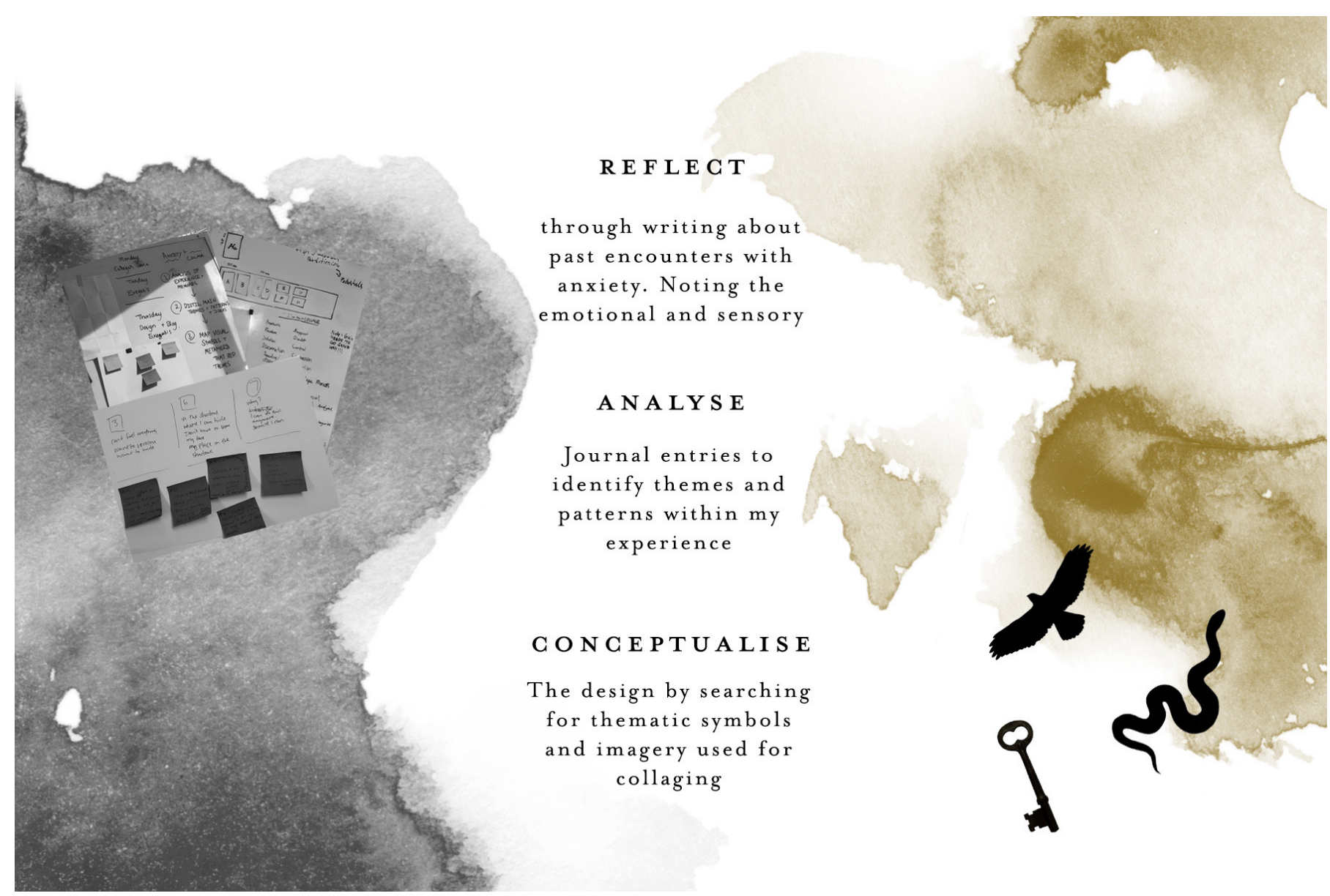

Fig 2. Diagrama do processo criativo Fonte: os autores 


\section{Registro no diário como método reflexivo}

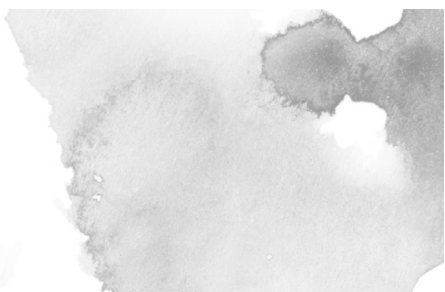

66 Reading through my writing has given me an insight to the way that anxiety is felt and experienced for me. I would describe it as a kind of duality of myself. It is a version of me that has its own traits and habits that characterise it and give weight to its presence. Emotions come and go, but with anxiety, it is a sort of deeply ingrained feeling that is almost imperceptible now. I cherish the moments that I am free from anxiety and expectantly dread its return. Anxiety is like heaviness on your shoulders, a shadow, an uncanny or weakened version of the self that preys on the mind, exploiting my mistakes and negative past experiences. I seem to find myself anxious about morality, social relationships, my own life and where I am heading, how I have missed out on my youth because I am overly ambitious towards my studies. The emotion that follows my bouts of anxious behaviour is regret. Sometimes this is because I act in ways that help me to avoid feeling anxious in the short term but results in self-destructive patterns. Anxiety brings out my-most immature or primitive nature, where I feel the need to survive stressful situations that seem threatening. For instance, these are situations where I could fail at something, and I perceive it to be catastrophic, thinking that It could destroy my future. This moment is where feelings of doubt arise. When my anxiety has been terrible, I stop engaging in everyday activities, in a sense, I give up on myself-bringing about a sense of meaninglessness. I tend to isolate myself from social interaction, as it seems I feel scared to share my experience. I write about how people's views towards mental illness and negative feelings, in general, seem to be that it is frowned upon and this had shaped a kind of self-stigma that left me feeling like I was alone and not ordinary. Like I needed to hide my anxiety. In a sense, my anxiety hides in plain sight; it presents myself to others as someone very motivated, organised, and conscientious. But beneath that lies an obsessive need to ensure that $I$ am in control of everything so that $I$ can avoid failure. An example of this is my nervous anticipation and questioning of new situations and feeling like I am wearing a mask.

Fig 3. Excerto de registro em diário

Fonte: os autores
O método primário desta pesquisa utiliza o diário para registrar a experiência pessoal de ansiedade da pesquisadora durante a criação do trabalho. Ao abordar o processo de registro no diário, exemplos de pesquisadores e seus encontros reflexivos com a prática serviram de referência. Um exemplo da tese de doutorado intitulada "O Processo da Fotografia Imersiva: Além do Cognitivo e do Físico" em que o diário expõe os encontros do autor durante a prática por meio de reflexões descritivas e emotivas, usando fotografias para ilustrar e evidenciar este encontro. De acordo com Steagall (2018), o registro pode integrar elementos do verdadeiro "drama interno" da pesquisa, com sua base intuitiva, sua linha de tempo hesitante e sua extensa reciclagem de conceitos e perspectivas.

Adotou-se abordagem semelhante nesta pesquisa, no sentido em que foi incluído um resumo amostral da prática projetual com colagem. Foram utilizados diferentes métodos para ajudar a gerar inspiração para os registros em diário. Para promover insights sobre os padrões e ocorrências coletivos, foi usado o mapeamento mental como uma ferramenta de geração de ideias ao longo da fase de ideação da pesquisa. No entanto, especialmente no diário, houve momentos em que a pesquisadora precisava apenas colocar algo no papel ou quebrar ideias que pareciam difíceis de explicar. Uma das técnicas para acompanhar o progresso e o aprendizado durante a criação das colagens foi dividir a entrada em categorias. Assim que o brainstorm geral da entrada foi concluído, foram criados os títulos rotulados como 'insights', 'perguntas' e 'desafios'. Ao final da entrada, era necessário verificar se o conteúdo estava alinhado com a forma como aquela ansiedade era sentida. Por exemplo, na entrada abaixo (figura 3), a pesquisadora escreve de forma a criar um diálogo contínuo consigo mesma. 


\section{Experimentação tipográfica}

O registro no diário, no sentido da escrita, foi uma forma que ajudou a analisar os padrões de comportamento e pensamentos da pesquisadora que emergiram do estado de ansiedade. Outros aspectos específicos desse método, que foram revelados às experiências sensoriais e emocionais, se deram através da condução e reflexão envolvendo mapas mentais, esboços e experimentações. As primeiras experimentações realizadas não foram, de fato, com a colagem em si. Em vez disso, o objetivo foi o de gerar representações visuais brutas e precisas da ansiedade da pesquisadora como conteúdo para a colagem. Isso levou às experiências com a tipografia e a ideia de distorções cognitivas: a manifestação subconsciente de pensamentos negativos dentro do tema da insegurança e da dúvida. Foi identificado que a sombra do self da pesquisadora, como um ponto de vista distorcido, trouxe à tona a possibilidade de ver as coisas diferentemente da realidade imediata - ou como seria tipicamente interpretado se não em um estado de ansiedade. Foram testadas aplicações empenadas com um efeito de lente que distorceu a fonte. Expandindo essas ideias, foi concebida uma maneira de mostrar a natureza penetrante, embora oculta, da ansiedade na construção da colagem. Foram criadas algumas aplicações repetitivas de tipografia impressa fina que são pensamentos literais da mente ansiosa utilizados como lentes de aumento que permitiam aproximar ou fixar esses padrões. Assim ocorre, de forma análoga, com a ansiedade, apesar de esses pensamentos não terem evidências concretas. A intenção foi trazer uma espécie de sensação de paranoia, na qual mentes ansiosas questionam se os pensamentos negativos são reais, algum medo ou forma de intuição.
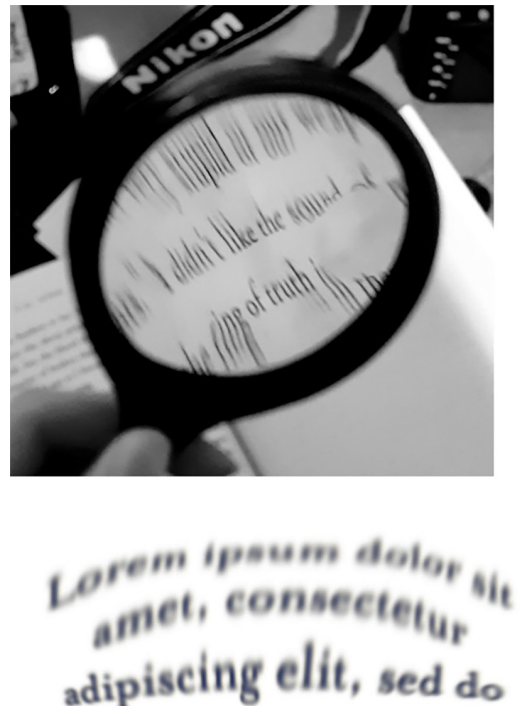
eiusmod tempor incididunt ut labore et dolore magna aliqua. Quis ipsum suspendisse ultrices gravida. Risus commodo viverra thaceenas aceumsan lacus
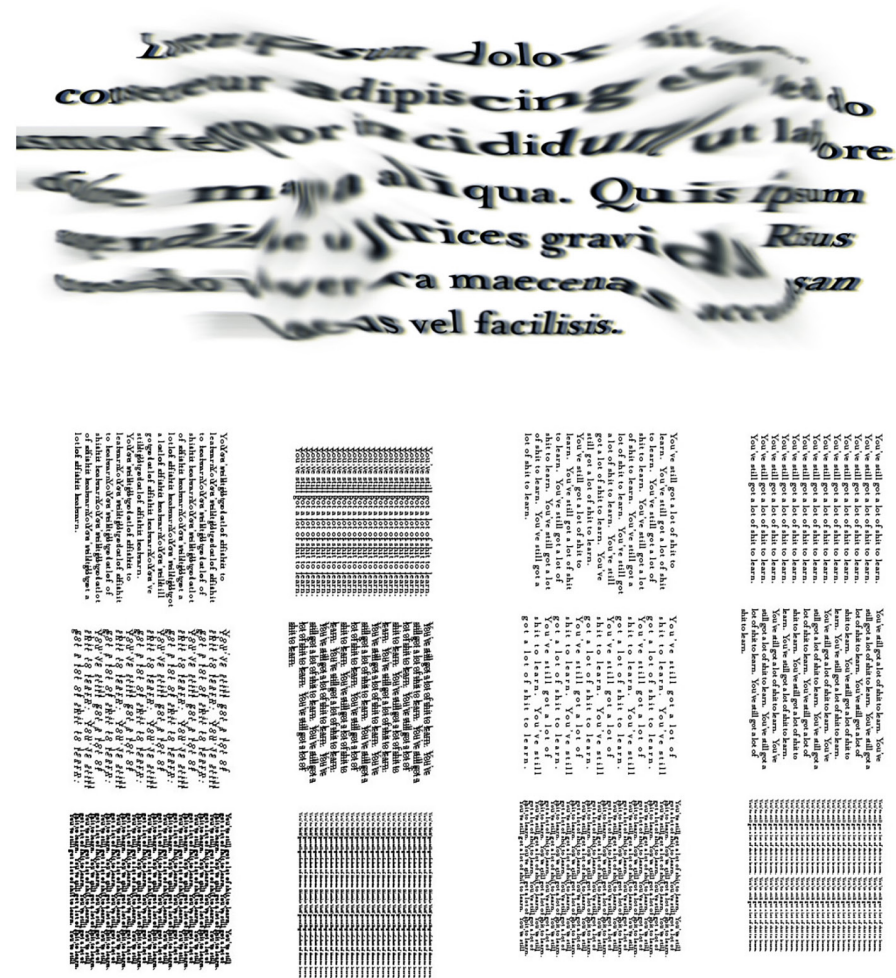


\section{Colagem como método para investigação qualitativa}

Além de ser uma forma de criação, a colagem pode ser usada como método de investigação e análise e que, ao lado da autoetnografia e da poesia, é considerada um modo de saber não tradicional. Quando a colagem está envolvida como parte do processo de pesquisa, o pesquisador pode se envolver profundamente no processo. De acordo com Butler-Kisber (2008, p4): "A colagem também pode ser útil na conceituação de um fenômeno, desenvolvendo diferentes facetas a fim de obter uma compreensão diferenciada dele". Uma vez que esta pesquisa investiga a experiência de ansiedade vivida pela pesquisadora, existem muitas facetas da experiência que a colagem permitiu entrelaçar, como a experiência sensorial de sintomas físicos, bem como transmitir emoções por meio de símbolos, cores e texturas, que materializam formas intangíveis. Irwin (2003, p.9) argumenta que "O processo de tomada de colagem usa inerentemente metáfora (similaridade ou comparação), metonímia (contiguidade ou conectividade) e (...) desafia a dicotomia do intelecto e dos sentidos".

$\mathrm{O}$ processo de colagem nesta pesquisa foi altamente intuitivo. Foram encontradas ilustrações e fotografias, tanto escaneadas fisicamente a partir de meios impressos quanto obtidas digitalmente por meio de busca de imagens. A partir daí, a pesquisadora começou a construir um banco de imagens para garantir que o processo de importação para o Photoshop fosse eficiente e eficaz. Conforme referido no diário, a respeito da seleção de imagens: "Escolhi conteúdos que me falavam no sentido de que os temas e a linguagem visual refletiam a forma como percebo minha ansiedade" (MICHIE, 2020, apêndice). Por exemplo, a primeira etapa foi optar por trabalhar com silhuetas texturizadas em preto e branco "(...) criando uma sensação de aspereza em contraste com a figura humana em minha colagem" (MICHIE, 2020, apêndice).

A reflexão ativa durante o processo de construção do agenciamento junto com pesquisas anteriores sobre ansiedade e ameaça, foi construída na compreensão de que a ansiedade era uma espécie de sombra no fundo de cada dia, uma sensação persistente de perigo, representando a dualidade do self. A partir dessa experimentação conceitual inicial, a pesquisadora pode experimentar com a implementação de símbolos que estavam conectados aos conceitos identificados de ameaça e dualidade. Por exemplo: optou-se por usar a imagem de uma serpente por ser uma representação metafórica do mal que caracteriza os pensamentos negativos de ansiedade. 


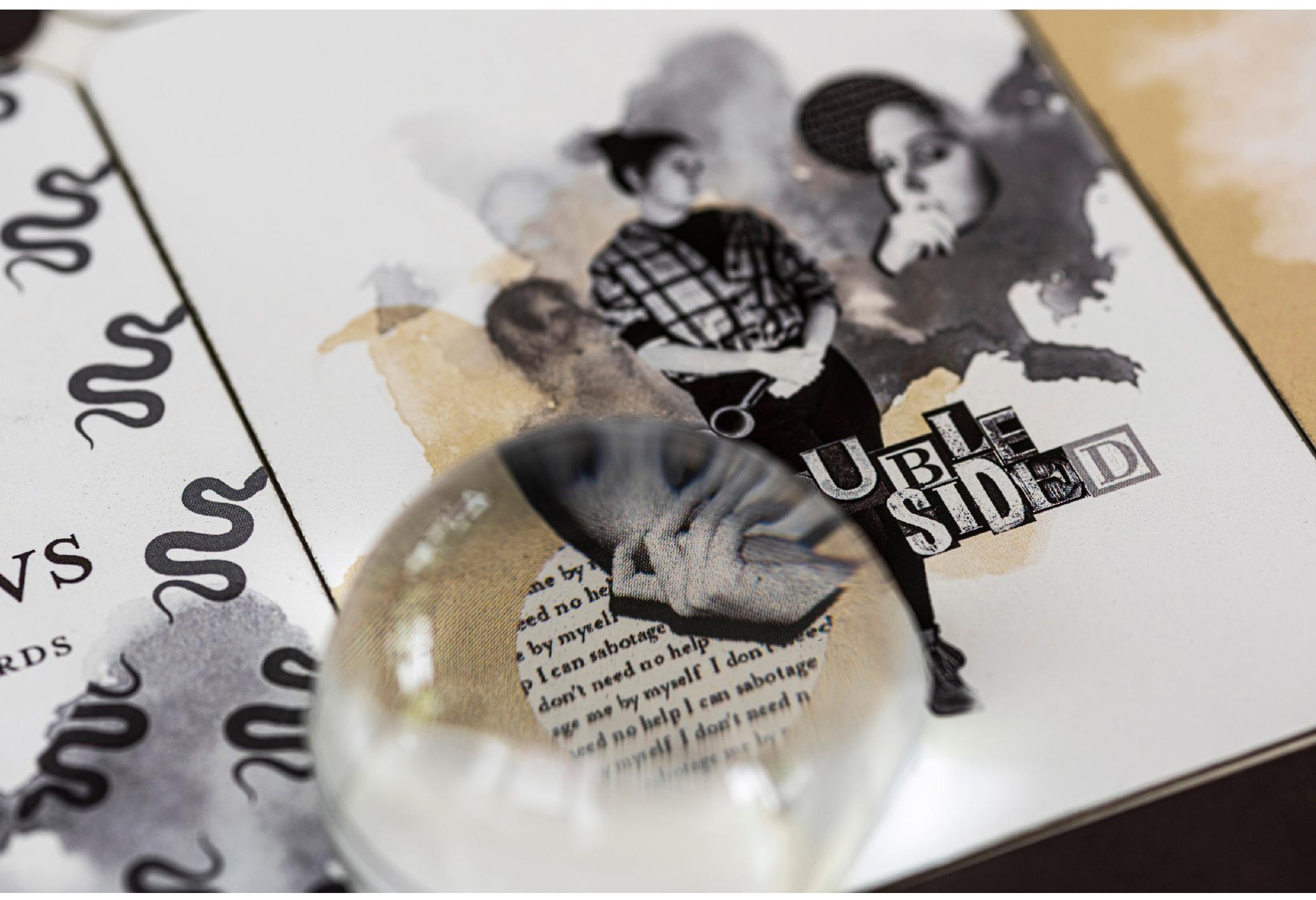

Fig 5. Colagem realizada em From Shadows

Fonte: os autores

\section{Comentários críticos}

\section{Ansiedade multifacetada}

Uma vez que o estudo foi conduzido por meio de uma investigação qualitativa de base fenomenológica, a forma como as informações foram navegadas se focou, principalmente, nas próprias experiências da pesquisadora traçando conexões com as imagens dentro das colagens. A partir de reflexões iniciais percebeu-se que a ansiedade não cabia dentro de uma caixa arrumada onde todas as emoções e dores pudessem ser atribuídas a uma causa singular. Foi descoberto, ainda, que alguns dos sintomas se enquadravam na categoria de "naturais", no sentido de que todas boa parte das pessoas já haviam experimentado esse nível de ansiedade na turbulência do dia a dia. 
Ao mesmo tempo, outros sintomas eram mais generalizados e podiam ser incluídos na doença da pesquisadora. Este foi o ponto responsável por questionar por que tentar categorizar a ansiedade. Concentrar-se em uma faceta, ou seja, na ansiedade existencial, seria excluir o resto ou grande parte da experiência. Neste sentido, um dos aspectos mais desafiadores dessa pesquisa foi gerenciar a complexidade da ansiedade como um tópico que pode ser visto de vários ângulos. Isso impulsionou a busca por padrões ou temas que surgiram de dentro de um relato pessoal, experimentando e testando formas capazes de comunicar as principais emoções e experiências sensoriais.

Outro desafio que surgiu com esta pesquisa foi a proximidade do tema com a pesquisadora. Foi considerado extremamente importante distanciar o ego longe o suficiente das memórias e ideias que estavam sob investigação, a fim de fornecer um relato honesto e sem agonia. A maneira de gerenciar esse distanciamento foi fazer uma pausa no projeto e falar com alguém de confiança sobre os problemas com a pesquisa. Essa pessoa geralmente era o irmão da pesquisadora, que ajudou a entender que quanto mais fundo fosse investigado e quanto mais pessoal fosse a experiência compartilhada pela pesquisadora, mais fortemente as pessoas seriam capazes de se relacionar com ela.

Por meio da prática do design, aprendemos que a colagem permitiu a pesquisadora trazer à tona as partes ocultas e às vezes negligenciadas de nossa experiência. Como prática, possibilitou recorrer a conexões entre ideias que se formam por meio das justaposições visuais do agenciamento. Essas imagens acabam tendo um significado diferente para a pesquisadora em relação ao estágio anterior da colagem devido à experiência que a imagem significa. É uma forma de mapear o passado por meio de uma reflexão intencional e codificar as várias nuances por meio da linguagem visual. Uma maneira simples de descrever o processo de pesquisa é que foi possível extrair um novo significado por meio de velhas memórias e comunicar visualmente a experiência pessoal ao conceituar as nuances da experiência vivida com a ansiedade.

\section{Temas e padrões}

Uma vez compilados todas os registros de entradas no diário, foi necessário percorrer e destacar temas e ideias específicas que apareceram várias vezes. Nesse sentido, o objetivo era filtrar os "objetos de valor" ou as ideias recorrentes mais críticas dentro da experiência mais ampla de ansiedade. Essas experiências foram destiladas em momentos de ansiedade que lidavam com pressão, liberdade, dúvida, controle, isolamento, apoio social e autocompaixão. A liberdade pode ser caracterizada por uma sensação de ansiedade que vem com a mudança, transição e responsabilidade - especificamente, quando o objetivo era preparar o resultado do último ano na 
Universidade, e novamente, na antecipação da formatura. Esta foi mais uma pressão decorrente das expectativas da sociedade de sucesso e realização, além da coação para ocultar a ansiedade decorrente do autoestigma sustentado pela pesquisadora, decorrente das percepções da sociedade em torno da saúde mental, e da dúvida quanto à capacidade de controlar e aceitar o fracasso e ser a melhor versão possível de si mesma. Para lidar com isso, o apoio social, concernente às pessoas ao redor e cuja voz ofereceu apoio e compartilhou experiências de ansiedade, ajudou a pesquisadora a alterar sua percepção do fenômeno e facilitou a autoaceitação.

Esses temas estão todos conectados no sentido de que são emoções com as quais cada pessoa tem experiência. $O$ estudo identificou que, no cerne da ansiedade, reside a insegurança e a dúvida. A pesquisadora passou a questionar como os sintomas psicológicos poderiam ser transformados em um relato mais digerível e humano da sua própria experiência. Para isso, o estudo voltou-se para a poesia, especificamente do gênero lírico - como mencionado anteriormente neste texto. A partir daí, foi possível identificar os pontos comuns entre a linguagem escrita e quais imagens o tom e o ritmo da poesia produziam na mente. Por exemplo, a descrição do som do pensamento ansioso como uma voz sussurrante maléfica que, ao ler o poema, ganhou forma com a imagem de uma cobra. Por meio de uma busca minuciosa de imagens e simbologias que alimentaram o entendimento sobre as associações sociais, culturais e teológicas que as imagens puderam adicionar múltiplas camadas de significado à colagem.

\section{Personificação da ansiedade e linguagem visual}

Multifacetada / dualidade / sombra oculta. Desenterrada, negligenciada, ignorância contrastada com iluminação, compaixão, paciência, curiosidade. Em termos de referências visuais, a inspiração veio de uma variedade de ilustradores de colagem de vários estilos, sobretudo surrealista. 0 tema da ansiedade e a sombra da personagem adicionaram um elemento de mistério e severidade ao estilo poético das imagens metafóricas. As cores branca e preta e as manchas de tinta como textura de fundo mantiveram o tom escuro das ilustrações. A cor amarelo-creme na colagem pretendia comunicar a disposição misteriosa e irracional da figura proeminente que sofre uma experiência multifacetada de ansiedade.

Foram realizadas pesquisas em torno do simbolismo e do significado em contextos sociais, culturais, históricos e teológicos para selecionar imagens que articulassem de forma adequada e precisa os temas e ideias que se pretendia retratar por meio das colagens. Muitas das imagens aludem à simbologia cristã e à mitologia romana / grega, visto que são amplamente difundidas como referências ocidentais à existência humana através das culturas e são símbolos que resistiram ao tempo. A seguir, apresentamos uma breve explanação sobre os principais símbolos que aparecem nas ilustrações de colagem. 
A representação mais adequada da sombra interna era a serpente. A bíblia cristã contém "passagens que descrevem as cobras como sutis, astutas, venenosas e de língua afiada" (WYNNE, 2018, p.132). A serpente simboliza o inimigo (mal), sabedoria de dupla face (traição), como quando apareceu pela primeira vez para Adão e Eva, coagindo-os ao pecado. Representa uma parte de nossa própria natureza que, se não for domesticada, pode ser uma ameaça para nós mesmos.

O segundo animal utilizado foi o falcão noturno, que representa a mente subconsciente como uma ameaça, embora se refira especificamente a uma ocorrência noturna. A sombra assume a forma do falcão noturno para representar a insônia, que é um sintoma sensorial de ansiedade - indicativo de que uma pessoa está habitualmente acordada à noite. Foi importante, ainda, usar o termo "falcão", que poderia ter sido substituído por "coruja", já que os falcões tendem a ser vistos como predadores no topo da cadeia alimentar. O símbolo da coruja, por sua vez, também foi utilizado, mas como elemento menos ameaçador da ansiedade.

Em referência à experiência da pesquisadora com ansiedade durante o ensino médio, bem como reconhecendo um senso necessário de autoconsciência ao abordar a ansiedade, adotou-se um grupo de imagens em torno das ideias contrastantes de conhecimento e ignorância. A primeira delas foi a estátua de Atena (Minerva) e sua coruja. "A Coruja de Atena é considerada um animal sagrado, fonte de sabedoria e julgamento ... o animal mais associado a ela tem uma visão noturna excepcional, simbolizando a capacidade de Atena ver quando os outros não podem" (GILL, 2018, p. 239). Atena e sua coruja representam a sabedoria idealizada que a sociedade promove, principalmente na educação. Por meio da análise, aprendeu-se que a ansiedade pode ser causada por uma insegurança em realizar aspirações devido à dúvida sobre a capacidade intelectual. No entanto, também é importante observar que a ansiedade tem o potencial de se tornar, por si só, um senso saudável de sabedoria, quando experimentada como um sistema de alerta saudável que ajuda na sobrevivência - e não como uma ameaça destrutiva.

Também foram incluídas imagens de estátuas e pedestais por motivos semelhantes mencionados no parágrafo acima. 0 pedestal se refere à pressão de sucesso e realização colocada sobre as gerações jovens na sociedade. Simboliza a tendência perfeccionista da ansiedade de se esforçar em direção às expectativas inatingíveis que se poderiam idolatrar inconscientemente, evitando e temendo o fracasso como resultado. Ao longo da história, as estátuas representam a transformação do homem e da própria humanidade - ou, a sua "evolução" entendida sob certa perspectiva religiosa e científica, como a forma mais elevada de criação, (HOFFMAN, 2017). Em um sentido mais profundo, estátuas significam moralidade, um tema que se manifesta nos registros do diário em relação ao medo da pesquisadora em relação aos erros do passado e a dificuldade em aprender a perdoar a si mesma. 
Outras imagens e símbolos que aparecem na série de colagem são: o buraco da fechadura, representando mistério, incerteza, potencial, liberdade e controle; a chave: representando iluminação, curiosidade e compreensão; pulmões: relacionamento, apoio, conforto, clareza e abertura; coração sangrento: emotividade, fragilidade, autopiedade, fraqueza e vulnerabilidade; o crânio trancado: uma fechadura na mente para significar, literalmente, a ausência de mente aberta. Em um reconhecimento mais sutil, esta última imagem também fala de ignorância, falta de autoconsciência ou negligência da voz interior. Nas ilustrações, é a prisão dentro da qual habita a sombra da ansiedade.

\section{Considerações finais}

From Shadows foi criado para incitar a reflexão e ressonância emocional por meio de pesquisas de design conduzidas pela prática. Neste sentido, esta pesquisa demonstrou como o uso da poesia, colagem e métodos autoetnográficos podem contribuir para um designer-pesquisador identificar e libertar a realidade da natureza da ansiedade, destilando e conceituando as nuances da experiência vivida por meio da comunicação visual.

o projeto resultou, além de uma pesquisa e de reflexões teóricas e pessoais, em artefatos na forma de cartões temáticos e ilustrativos que incentivam o público a refletir sobre suas próprias emoções enquanto interagem com as peças.

1 Tradução para o português: Marcos Mortensen Steagall

\section{Referências}

ALPERT, R.; HABER, R. Anxiety in academic achievement situations. In: The Journal of abnormal and social psychology, v. 61, n. 2, p. 207-215, 1960.

BUTLER-KISBER, L. Collage as Inquiry. Handbook of the Arts. In: BUTLER-KISBER, L. Qualitative Research: Perspectives, Methodologies, Examples, and Issues. Newbury Park: Sage Publishing, p. 265- 277. 2008. https://dx.doi.org/10.4135/9781526435408.n7

DENZIN, N. K., \& Lincoln, Y. S. The landscape of qualitative research. Newbury Park: Sage Publishing, 2008.

ELLIS, C., ADAMS, T. E., \& BOCHNER, A. P. Autoethnography: An Overview. Historical Social Research/ Historische Sozialforschung, p.273-290, 2011.

GILL, N. S. 4 Symbols of the Greek Goddess Athena. ThoughtCo, 2018.

HEIDEGGER, M. Basic writings: from Being and time (1927) to The task of thinking (1964). Philpapers, 1977. Disponível em: <https://philpapers.org/rec/HEIBWF>. Acesso em: $20 \mathrm{dez} 2020$. HEMBREE, R. The nature, effects, and relief of mathematics anxiety. In: Journal for research in mathematics education, v. 21, n. 1, p. 33-46, 1990. 
HOODA, M.; SAINI, A. Academic anxiety: an overview. Educational Quest, v. 8, n. 3, p. 807-810, 2017. DOI:10.5958/2230-7311.2017.00139.8

HOFER, G. Tarot cards: an investigation of their benefit as a tool for self reflection. 2009. 102f. Dissertação (Mestrado em Artes). University of Victoria, Victoria, 2009.

HOFFMAN, R. What does a statue truly symbolize? Chron, 2017. Disponível em: < https:// www.chron.com/neighborhood/cleveland/opinion/article/What-does-a-statue-truly-symbolize-12042452.php>. Acesso em: $20 \mathrm{dez} 2020$.

IGWENAGU, C. Fundamentals of research methodology and data collection. LAP - Lambert Academic Publishing, 2016.

INGS, W. Managing heuristics as a method of inquiry in autobiographical graphic design theses. In: International Journal of Art \& Design Education, v. 30, n. 2, p. 226-241, 2011.

IRWIN, R. Curating the aesthetics of curriculum/leadership or caring for how we perceive running/guiding the course. University of British Columbia: The Department of Curriculum Studies, Artful Salon, 2003.

KIERKEGAARD, S. The Essential Kierkegaard. Princeton University Press, 2000.

KORSTJENS, Irene; MOSER, Albine. Practical guidance to qualitative research. Part 2: Context, research questions and designs. European Journal of General Practice, v. 23, n. 1, p. 274-279, 2017.

MORTENSEN STEAGALL, M., \& Ings, W. Practice-led doctoral research and the nature of immersive methods. In: DAT Journal, 2018, 3(2), 392-423. https://doi.org/10.29147/dat.v3i2.98 MORTENSEN STEAGALL, M. The Process of Immersive Photography: Beyond the Cognitive and the Physical. 2018, 228f. Tese (Doutorado em Artes e Design). Auckland Univeristy of Technology, Auckland, 2018.

MOSS, D. Anxiety disorders. In: D. Moss; A. McGrady, \& T. Davies (eds.) Handbook of mind-body medicine for primary care. Newbury Park: SAGE Publications, 2003, p.359-376. DOI: 10.4135/9781452232607.n26

ORR, G. Poetry as Survival: poets on their art and craft. Athens: University of Georgia Press, 2002. SWIFT, P. et al. Living with anxiety: Understanding the role and impact of anxiety in our lives. In: Mental Health Awareness Week, 2014. Disponível em: < https://www.mentalhealth. org.uk/sites/default/files/living-with-anxiety-report.pdf>. Acesso em: $20 \mathrm{dez} 2020$.

QUINN PATTON, M. Qualitative research and evaluation methods. Newbury Park: SAGE Publishing, 1980.

RICHARDSON, L.; ST PIERRE, E. Writing: a method of inquiry. In: DENZIN, N. K.; LINCOLN, Y. S. (eds.). Collecting and Interpreting Qualitative Materials. Newbury Park: SAGE Publishing, 1998, p. 473-499.

STEIMER, T. The biology of fear- and anxiety-related behaviors. In: Dialogues in clinical neuroscience. v. 4, n. 3, p. 231-249, 2002. DOI:10.31887/DCNS.2002.4.3/tsteimer

TROCHIM, W. M.; DONNELLY. Research Methods: The Essential Knowledge Base. Boston: Cengage Learning, 2016.

VOELKER, R. Academic Anxiety. JAMA, v. 284, n. 12, p. 1506-1506, 2000.

WILSON, E. R. The greatest empire: a life of Seneca. New York: Oxford University Press, 2014. WYNNE, M. The Meaning of the Snake or Serpent as a Christian Symbol in the Bible. Synonym, 2018. Disponível em: <https://classroom.synonym.com/ meaning-snake-serpent-christian-symbol-bible-5567.html>. Acesso em: $20 \mathrm{dez} 2020$.

Recebido: 08 de janeiro de 2021. Aprovado: 10 de fevereiro de 2021. 